\title{
Evaluation of the Efficacy of Tranexamic Acid in the Management of Menorrhagia
}

\section{P. Yamini Shoba Vani ${ }^{1}$, K. Nirmala' ${ }^{2}$, Parlapally Shashi jyothsna ${ }^{3}$}

Section: Healthcare

Sci. Journal Impact

Factor: 6.1 (2018)

ICV: 90.90 (2018)

(c) (7) (8)

Copyright@IJCRR

\author{
'Associate Professor, Department of Gynecology and Obstetrics, CKM, Kakatiya Medical College, Warangal, Telangana, India; \\ ${ }^{2,3}$ Assistant Professor, Department of Gynecology and Obstetrics, CKM, Kakatiya Medical College, Warangal, Telangana, India.
}

\section{ABSTRACT}

Background: Abnormal uterine bleeding (AUB) negatively affects physical, emotional, sexual and professional aspects of the life of women, worsening their quality of life.

Objectives: Study is to know the efficacy of tranexamic acid in Abnormal uterine bleeding in our hospital.

Methods: The present study was conducted in 50 patients with complaints of regular excessive menstrual flow were included. The study included measurement of menstrual blood loss, duration of bleeding, number of sanitary pads used for two menstrual cycles in women who complained of regular excessive menstrual bleeding using pictogram and PBAC Scoring (Pictorial blood loss assessment charts ). The oral drug, tranexamic acid $500 \mathrm{mg}$ thrice daily was given to these women after obtaining who had mean menstrual blood loss of more than $80 \mathrm{ml}$, according to PBAC scoring more than 100 , based on the assessment in the previous two menstrual cycles.

Results: Significant decrease in the amount of menstrual bleeding was noticed in 39 out of 50 women. Mean menstrual blood loss during one pre-treatment cycle was dropped to $60 \mathrm{ml}$ from $120 \mathrm{ml}$. The mean decrease was $54.7 \mathrm{ml}$ in one cycle. The decrease in the amount of blood loss was about $45 \%$ to $50 \%$, which was indicating that the drug was very effective in decreasing blood loss. Increase in haemoglobin concentration is also noticed. But there was not much difference in the duration of menstrual bleeding. $74 \%$ of them had haemoglobin less than $10 \mathrm{gm} \%$, after treatment with tranexamic acid and oral iron therapy, this percentage was decreased to $42 \%$.

Conclusions: Treatment with tranexamic acid increases the quality of life of women by reducing the impairment of social activities and impairment at work and there is substantial improvement in overall well being.

Key Words: Tranexamic acid, PBAC Scoring (Pictorial blood loss assessment charts), Blood loss

\section{INTRODUCTION}

Abnormal menstrual bleeding is the term currently used for changes in menstruation resulting from increased volume, duration, or frequency. Abnormal uterine bleeding (AUB) negatively affects physical, emotional, sexual and professional aspects of the life of women, worsening their quality of life. ${ }^{1}$ AUB was reported to occur in $9-14 \%$ women between menarche and menopause. The prevalence varies in each country. In India, the reported prevalence of AUB was around $17.9 \%{ }^{2}$ The prevalence was increasing with age and peaking just before menopause. AUB is one of the most common reason for referral to a gynaecologist. It has been found that once women were referred to a gynaecologist, $60 \%$ of women with menorrhagia will have a hysterectomy within 5 years, accounting for up to $75 \%$ of all hysterectomies performed worldwide. About half of all women who proceed with hysterectomy for their heavy bleeding have a normal uterus removed. The degree of blood loss can cause significant discomfort, social embarrassment and inconvenience as well as medical risks such as chronic iron deficiency anaemia. So, such women wish to undergo medical/surgical treatment to eliminate or decrease the problem. The main objective of treatment is to achieve symptomatic relief, improve women's quality of life and anaemia. ${ }^{3}$

Tranexamic acid causes a 50\% reduction in menstrual blood loss and improves the quality of women's life. ${ }^{3}$ It is safe and highly effective for the treatment of heavy menstrual bleeding. Patients with AUB should be offered medical treatment

\section{Corresponding Author:}

Dr. K. Nirmala, Assistant Professor, Department of Gynecology and Obstetrics, CKM, Kakatiya Medical College, Warangal, Telangana, India; Phone: 9194907 92358; Email: harinath111111@gmail.com.

ISSN: 2231-2196 (Print)

Received: 27.10 .2020
ISSN: 0975-5241 (Online)

Revised: 23.10 .2020
Published: 14.12 .2020 
with tranexamic acid before the decision is made for surgery. The purpose of this study is to know the efficacy of tranexamic acid in AUB (Abnormal uterine bleeding) in our hospital.

\section{MATERIALS AND METHODS}

This study was carried out in the department of Obstetrics and Gynaecology, in Mamata General Hospital, Khammam from October 2015 to September 2017. For this, 50 women were selected for the study from patients who attended the hospital outpatient department [ OPD ] with complaints of menorrhagia during the study period and fulfilled the selection criteria. patients who complained of regular excessive menstrual bleeding during cycles between 24 to 35 days were considered. The written consent and Ethical clearance was obtained from the institutional committee (M155114069).

\section{Inclusion Criteria}

Women aged 18-45 years with a complaint of menorrhagic cycles, Women with the duration of cycles between 24-35 days.

\section{Exclusion Criteria}

Any present pelvic pathology like large uterine fibroids who need surgery, adenomyosis and endometriosis, Systemic diseases like platelet disorders or coagulopathies, Women with History of Renal or Hepatic impairment, previous thromboembolic disease and peptic or intestinal ulceration. Concomitant use of oral contraceptives or non-steroidal anti-inflammatory drug and Pregnancy. Before prescribing Tranexamic acid, Complete history regarding present and past menstrual cycles, medical, surgical and family history should be taken. General examination, Per abdomen, Per speculum examination was done.

Investigations like complete blood picture, complete urine examination, Thyroid, Liver and Renal functional tests, Urine pregnancy test and Ultrasonography were done for all the patient and menstrual blood loss assessment was done for two pre-treatment menstrual cycles using pictogram, serving as controls and was compared with 3 post-treatment cycles. Treatment started after taking consent from the patient that they are willing to participate in our study and agree to take treatment with oral tab tranexamic acid $500 \mathrm{mg}$ thrice daily starting from $1^{\text {st }}$ day of periods and continued for 5 days during periods for 3 months.

Pictogram was shown to patients and asked them to tell how their pad was soaked and the PBAC score was given. Then they were given copies of a pictogram to document the number of sanitary pads/towels/tampons used and taught them how to write the number of sanitary pads/towels/tampons used each day given in separate columns. Extra Score is added if there was the presence of any clots or episodes of flooding. Each day scoring was added to get a final score for the entire period and thus depending on this score, indirectly menstrual blood loss was assessed. PBAC score more than 100 was considered to have menstrual blood loss more than $80 \mathrm{ml}$ and hemorrhagic. Then patients who were considered as having menorrhagia were prescribed tablet tranexamic acid $500 \mathrm{mg}$ thrice daily from $1^{\text {st }}$ day of the menstrual cycle to $5^{\text {th }}$ day for three next consecutive cycles.

\section{Follow-up}

Follow-up interval was monthly after periods during the treatment course, patients were interviewed 4 times, thrice during treatment and once after treatment. At each visit amount of bleeding, number of bleeding days, the passage of clots, number of sanitary pads used and any episodes of flooding were asked and assessed using pictogram and PBAC score was given. Adverse effects if any were also recorded. Patient satisfaction and well being are enquired. Efficacy of the drug was analyzed before and after treatment with tranexamic acid. All women were advised to use the same type of sanitary products which have similar absorbent capacities.

\section{RESULTS}

\section{Demographic distribution}

Tab Tranexamic acid $500 \mathrm{mg}$ thrice daily for 5 days starting from $1^{\text {st }}$ day of menstruation was given to the patients who had objectively measured blood loss of more than $80 \mathrm{ml}$ per cycle and PBAC score more than 100 per cycle for a total of 50 women with Abnormal uterine bleeding (Table 1).

Table 1: Demographic distribution of women with AUB $[\mathbf{n}=\mathbf{5 0}]$.

$\begin{array}{lll}\text { Age in years } & \begin{array}{l}\text { Number of women } \\ \text { with AUB }\end{array} & \begin{array}{l}\text { Percentage } \\ 18-26\end{array} \\ 27-35 & 20 & 16 \% \\ 36-45 & 22 & 40 \% \\ \text { Total } & 50 & 44 \% \\ \text { Parity } & & 100 \% \\ \text { Unmarried } & 2 & \\ \text { Nullipara } & 5 & 4 \\ \text { Para 1 } & 4 & 10 \\ \text { Para 2 } & 29 & 8 \\ \text {.Multi Para } & 10 & 58 \\ \text { Clinical findings } & & 20 \\ \text { Normal uterine size } & 37 & 74 \\ \text { [n=50] } & & \end{array}$


Table 1: (Continued)

\begin{tabular}{|c|c|c|}
\hline Age in years & $\begin{array}{l}\text { Number of women } \\
\text { with AUB }\end{array}$ & Percentage \\
\hline Bulky uterus [10 wks] & 13 & 26 \\
\hline \multicolumn{3}{|c|}{ Adnexal Pathology $[\mathrm{N}=50]$} \\
\hline Normal Ovaries & 48 & 96 \\
\hline Cystic Ovaries & 2 & 4 \\
\hline
\end{tabular}

\section{Distribution of women}

Women with abnormal uterine bleeding were more in the age group of 36 to 45 years indicating increased prevalence in the perimenopausal age group. $58 \%$ of women with AUB were para 2. Most of the women were vasectomized after two living children. The normal uterus was found in $74 \%$ of women. $26 \%$ of them showed bulky uterus [10 wks] in which other causes for uterine enlargement like leiomyoma, adenomyosis and pregnancy causes were excluded. The bulky uterus may be due to multiparity (Table 2).

There was no adnexal pathology detected in $96 \%$ of women and only $4 \%$ had simple cystic ovaries.

Table 2: Distribution of women by Haemoglobin findings before and after treatment

\begin{tabular}{lcl} 
Findings & No. Women & Percentage \\
Haemoglobin [ Gm\% ] before treatment & \\
$<10$ & 37 & 74 \\
10 & 11 & 22 \\
$>10$ & 2 & $4-$ \\
Haemoglobin [ Gm\% ] after treatment & \\
$<10$ & 21 & 42 \\
10 & 22 & 44 \\
$>10$ & 7 & 14 \\
TOTAL & 50 & $100 \%$ \\
\hline
\end{tabular}

\section{Effect of drug on PBAC scoring and amount of bleeding}

$74 \%$ of women had haemoglobin less than $10 \mathrm{gm} \%$. Women with haemoglobin more than 10 gm was only $4 \%$. The factors contributing to anaemia were excessive menstrual blood loss and nutritional deficiencies. The percentage of patients who had $\mathrm{Hb} \%$ more than $10 \mathrm{gm} \%$ increased to $14 \%$ after treatment with Tranexamic acid. The increase was due to treatment with iron therapy and also due to decreased menstrual blood loss (Table 3).
Table 3: Effect of drug on PBAC scoring and amount of bleeding

\begin{tabular}{ll} 
of bleeding & $\begin{array}{l}\text { Blood loss in } \mathrm{mL} \\
(\text { Mean } \pm \text { SD) }\end{array}$ \\
\hline $\begin{array}{l}\text { Effect of drug on PBAC scoring } \\
\text { Before treatment }\end{array}$ & $150+22$ \\
After treatment & $82+16$ \\
$\begin{array}{l}\text { Effect of drug on the amount of } \\
\text { bleeding }\end{array}$ & \\
Before treatment & $120+17$ \\
After treatment & $60+12$ \\
\hline
\end{tabular}

\section{Effect of Drug on menstrual blood loss}

After treatment with tranexamic acid, the mean PBAC score reduced from $150 \pm 22$ to $82 \pm 16$ and the mean amount of menstrual bleeding reduced from $120 \pm 17 \mathrm{ml}$ to $60 \pm 12 \mathrm{ml}$ indicating that tranexamic acid is a more effective drug for women with abnormal uterine bleeding (Table 4). The mean reduction in the amount of blood loss was about $54 \mathrm{ml}$ per cycle. LE 9: effect of

Table 4: Drug on menstrual blood loss in women with abnormal menstrual bleeding

\begin{tabular}{lcc}
$\begin{array}{l}\text { Drug on menstrual blood } \\
\text { loss in women with abnor- } \\
\text { mal menstrual bleeding }\end{array}$ & $\begin{array}{c}\text { Number of } \\
\text { women }\end{array}$ & Percentage \\
$>50 \mathrm{ml}$ & 39 & 78 \\
$<50 \mathrm{ml}$ & 11 & 22 \\
total . & 50 & 100 \\
effect of the drug on a & & \\
percentage of reduction of & & \\
menstrual blood loss & 6 & 12 \\
$<35 \%$ & 5 & 10 \\
$35 \%-40 \%$ & 10 & 20 \\
$40 \%-45 \%$ & 21 & 42 \\
$45 \%-50 \%$ & 5 & 10 \\
$50 \%-55 \%$ & 3 & 6 \\
$55 \%-60 \%$ & 50 & $100 \%$ \\
TOTAL & & \\
\hline
\end{tabular}

\section{Effect of drug on the duration of bleeding}

Majority of women [ $62 \%$ ] experienced their amount of menstrual blood loss reduced up to $40 \%-50 \%$. From the above table over all $78 \%$ of women experienced their amount of menstrual blood loss reduced to significant levels showing that the drug is very effective in reducing menstrual blood loss (Table 5). There was a significant reduction in the usage of the number of sanitary pads which was found in patients treated with Tranexamic acid. Found that there was not much 
significant difference in the duration of menstrual bleeding between the pre-treatment and treatment cycles.

Table 5: Effect of drug on the usage of sanitary pads
per cycle and duration of bleeding
$\begin{array}{lc}\text { Effect of drug on the usage of sanitary pads per cycle in } \\
\text { the number }\end{array}$
\begin{tabular}{lc} 
Before Treatment & $21 \pm 4$ \\
After Treatment. & $10 \pm 2$. \\
Effect of drug on the duration of bleeding in days & \\
Before Treatment & $8 \pm 2$ \\
After Treatment. & $6 \pm 1$ \\
\hline
\end{tabular}

\section{Correlation of drugs effects with patient's sat-} isfaction and acceptability

Minor side effects, mostly of gastrointestinal origin were seen only in 5 out of 50 women. Out of this, only 2 women dropped out of the study because of nausea, vomiting indicating that intolerable side effects are very minimal with the drug, despite which there was discontinuation among 2 women but we followed them during the study period.

From the above table, $84 \%$ of the patients were satisfied with the drug and $16 \%$ were unsatisfied because of side effects and only minimally reduced blood loss. Patient acceptability was only $68 \%$ and $32 \%$ of patients were not ready to continue the drug because of the need for intake of drug in every cycle for prolonged periods. There is a decrease in the percentage of acceptability though patients were satisfied. This is because of the need for treatment in subsequent cycles for a prolonged period and relatively high cost of the drug.

Dropouts were only 2 women after $1^{\text {st }}$ treatment cycle because of side effects but we followed these 2 patients during the study period and 14 more women were dropped out after $3^{\text {rd }}$ cycle because of need for treatment in subsequent cycles for a prolonged period and high cost of the drug. Among the 14 patients, 6 of them reported only minimal amount of blood loss which was reduced.

\section{DISCUSSION}

The present study was a prospective clinical study. In this study, we selected fifty patients aged $18-45$ years who have attended the outpatient department of Obstetrics and Gynaecology in Mamata General Hospital with complaining of regular heavy menstrual bleeding and recruited into the study, based on inclusion and exclusion criteria (Table 1). We compared 2 pre-treatment cycles with 3 post-treatment cycles. Majority of the women with abnormal uterine bleeding were in the age group of 36 to 45 years which was near similar to previous study. ${ }^{4-8}$
In the present study, fifty women were treated with tranexamic acid $500 \mathrm{mg}$ orally thrice daily for five days starting from day 1 after taking consent from the women. We treated women in our hospital with low dose tranexamic acid to improve and maintain the compliance of the women during the study period and also to minimize gastrointestinal disturbances. In Preston JT et al. study, menstrual blood loss was measured using the alkaline haematin method. ${ }^{4}$ Haematological assessments were made both at the beginning and at the end of the study. Questionnaires were given to assess subjective endpoints and the patients were asked to report any adverse events during all the cycles. Bonnar J et al. In three control menstrual cycles and menstrual periods during treatment, menstrual blood loss was assessed by the alkaline haematin method. ${ }^{5}$

The duration of bleeding, patients' estimation of blood loss, sanitary towel usage and unwanted events were noted. In Callender ST et al. study, the menstrual blood loss was measured subjectively. ${ }^{6}$ In Freeman EW et al. study they assessed the efficacy and safety of 2 dose regimens of a novel, oral tranexamic acid formulation by observing primary efficacy endpoints which were mean MBL reduction from baseline, Mean reductions of MBL that were considered significant by subjects and mean reductions of MBL $>50 \mathrm{ml} /$ cycle from baseline and also adverse events were also assessed. ${ }^{8}$

In this study, we observed the efficacy of tranexamic acid by assessing the menstrual blood loss by pictorial blood loss assessment chart. It was a simple, cheap and also been found to correspond well with alkaline haematin test because most of the patients were from rural areas and belonged to lower socioeconomic status. Adverse events and patient satisfaction rates were also noted and acceptability of patient i.e., willingness to continue the treatment after study period was also assessed in our study, to know the efficacy of tranexamic acid in women with menorrhagia. It is reported that that tranexamic acid was a safe and effective form of medical therapy in women with menorrhagia and is highly likely to normalize blood loss in women losing 80 to $200 \mathrm{ml}$ before treatment. ${ }^{4}$ In their study, there were no serious adverse events reported with tranexamic acid.

Sanitary towel usage was significantly reduced, but the duration of bleeding was not affected. Mean duration of bleeding was $5.5 \pm 1$ before treatment with tranexamic acid and it was reduced to $4.9 \pm 1$ after treatment. A mean number of sanitary towels used before treatment were $23 \pm 7$ and they were reduced to $20 \pm 6$. (Table-5) In their study, the frequency of unwanted events was slightly increased during treatment with tranexamic acid for menorrhagia, they were symptoms arising during menstruation and may not be related to the treatment. The frequency of nausea was increased with tranexamic acid. These adverse effects of tranexamic acid were mild and minimal and they were related to the gastro- 
intestinal disturbance. Patient acceptability is an integral aspect of every care assessment. Patient satisfaction was strong for tranexamic acid, which was $77 \%$, as indicated by the desire to continue treatment after the analysis (figure-1). Four patients withdrew from the study, three out of the four patients described an unwanted event such as nausea, headache and dizziness as the reason for withdrawal from the treatment. The discontinuation rate was $15 \%$ in the study done by Bonnar $\mathrm{J}$ et al. overall indicating that tranexamic acid is an effective medical therapy in women with regular heavy menstrual bleeding. ${ }^{5}$

There was no effect on the duration of bleeding and a reduction in the number of napkins used. With the dosage schedule used in their trial, the side effects were insignificant and only 2 patients complained of a headache. ${ }^{6}$ In the study done by Callender et al. discontinuation rate was up to $20 \%$. In their discussion they concluded that in most women tranexamic acid did not return the blood loss to normal; nevertheless, it is likely to be a helpful agent where hormone therapy is not indicated and hysterectomy is not desired. ${ }^{6}$

The mean menstrual blood loss was reduced from baseline by $40 \%$. Reduction in mean menstrual blood loss was 69.6 $\mathrm{ml}$ after treatment with tranexamic acid from 172.3 \pm 95.6 [ 83.1-747.3 . $^{7}$ Improvements in both menstrual blood loss and health-related quality of life parameters were observed during the first treatment cycle and were maintained throughout the 6-month study duration. ${ }^{8}$

Freeman EW et al. found that the mean menstrual blood loss change from baseline in low dose tranexamic acid $650 \mathrm{mg}$ received group was $26 \%$ and in high dose tranexamic acid $1.3 \mathrm{gm}$ received group was $39 \% .{ }^{8}$ Percentage of discontinuation in low dose tranexamic acid group in their study group was $9 \%$ and with a higher dose of tranexamic acid was $13 \%$.

The majority of patients $87 \%$ in their study group reported adverse effects, four women using tranexamic acid withdrew from their study because of adverse effects, which were considered not or probably not related to treatment. The most frequently reported adverse effects in $\geq 5 \%$ of tranexamic acid treated women were viral upper respiratory infection, fatigue, musculoskeletal pain, arthralgia, myalgia and nasal congestion. The majority of adverse effects in both low and high dose tranexamic acid groups were menstrual discomfort/cramps, headache, back pain and nausea. We reported mean menstrual blood loss reduced from the baseline which was $44 \%$ and it was a greater reduction compared to a lower dose of tranexamic acid similar to reported previously. ${ }^{4,6-8}$ Tranexamic acid is an effective drug in women with abnormal uterine bleeding and who doesn't want to undergo surgery or who wants to conceive, as tranexamic acid doesn't alter the ovarian function and has no effect on ovulation, so it is the drug of the first choice for medical therapy among women in the reproductive age.
Anaemia was more prevalent at baseline up to $96 \%$ in our study, because most of the patients belonged to lower socioeconomic status, most of them suffered from nutritional deficiency anaemia and it was further aggravated by heavy menstrual bleeding. Mean haemoglobin levels increased from baseline $1.6 \pm 1$ after treatment with tranexamic acid and oral iron. It is an effective drug for women who have heavy menstrual blood loss and became anaemic, some improvement in haemoglobin levels was observed after treatment with tranexamic acid as there was a significant reduction of menstrual blood loss along with oral iron therapy.

Sanitary towel usage was significantly reduced from mean usage $21 \pm 4$ before treatment with tranexamic acid to $10 \pm 2$ after treatment which was comparable to Bonnar J et al, indicating that tranexamic acid effectively reduces the sanitary pad usage, reduces the expenditure towards the purchase of sanitary napkins and thereby diminishes health problems due to unhygienic conditions. In our study these side effects were very minimal, indicating that tranexamic acid is an effective and well tolerable drug of the first choice in women requiring medical therapy for abnormal uterine bleeding. Out of the fifty women, only two dropped out of the study because of nausea and vomiting. Intolerable side effects were very minimal and there were no severe side effects observed with tranexamic acid when compared to other medical therapy used for regular heavy menstrual blood loss. In Freeman EW et al. study four patients withdrew because of adverse effects. Satisfaction rate was about $84 \%$ but acceptability rate was only $68 \%$ in our study which was relatively less compared to Bonnar J et al. [77\%]. Less acceptability rate and more discontinuation rate was attributed to the relatively high cost of drug and need for oral medication for subsequent cycles for a longer period.

\section{CONCLUSION}

About $90 \%$ of menstrual blood loss occurs within the first three days of menstruation both in normal menstruation and in menorrhagia. Treatment to minimise menstrual blood loss would have achieved by giving during these three days. Tranexamic acid during these three days would reduce menstrual blood loss by over half and return menstrual bleeding to normal for most women. Studies mentioned in our discussion showed that there was a reduction in menstrual blood loss by up to $50 \%$. Tranexamic acid given during menstruation is a safe, well-tolerated and highly effective treatment in women with abnormal menstrual bleeding and is highly likely to normalise blood loss in women losing $80 \mathrm{ml}$ to 200 $\mathrm{ml}$ before treatment. Women with abnormal uterine bleeding should be offered medical treatment with tranexamic acid before a decision is made for surgery. It may be utilized as first-line therapy in AUB. All the treatment options should be discussed with the women, giving her sufficient informa- 
tion about the risks and benefits of the drug and surgical interventions, for her to make an informed choice about the management of her problem.

\section{ACKNOWLEDGEMENT}

Authors acknowledge the immense help received from the scholars whose articles are cited and included in references to this manuscript. The authors are also grateful to authors/ editors/publishers of all those articles, journals and books from where the literature for this article has been reviewed and discussed.

\section{Conflict of interest-Nil}

\section{Financial support-Nil}

\section{REFERENCES}

1. Liuz, Doan Q V, Blumenthal P, Dubois RW.A systemic review evaluating health-related quality of life, work impairment, and health- care costs and utilization in abnormal uterine bleeding. Value Health, 2007, 10(03),183-194.
2. Sharma A, Dogra. Trends of AUB in tertiary centre of Shimla hills. J Midlife Health 2013: 4,67-8.

3. National Institute for health and care Excellence. NICE clinical guideline 44, Heavy menstrual bleeding. London (UK), National Health Service. 2007.

4. Preston JT, Cameron IT, Adams EJ, Smith Sk. Comparative study of tranexamic acid and norethisterone in the treatment of ovulatory menorrhagia. Br J Obstet Gynaecol 1995;102(5):4016.

5. Bonnar J, Guillebaud J, Kasonde JM, Sheppard BL. Clinical applications of Fibrinolytic inhibition in gynaecology. J Clin Pathol 1980;33 (14):55-9.

6. Callender ST, Warner GT, Cope E. Treatment of menorrhagia with tranexamic acid. A double-blind trial. Br Med J 1970;4(5729):214-216.

7. Lukes AS, Moore KA, Muse KN. Tranexamic acid treatment for heavy menstrual bleeding: A randomized controlled trial. Obstet Gynecol 2010;116(4):865-875.

8. Freeman EW, Lukes A, VanDrie D, Mabey RG, Gersten J, Adomako TL. A dose-response study of a novel, oral tranexamic formulation for heavy menstrual bleeding. Am J Obstet Gynecol 2011; 205(4):319.e1-319.e7. 